SAARC J. Agri., 12(1), 01-08(2014)

\title{
COMBINING ABILITY ANALYSIS FOR GRAIN YIELD AND ITS ATTRIBUTES IN RICE (Oryza sativa L.)
}

\author{
B. P. Mallikarjuna*, N. Shivakumar ${ }^{1}$, J. Devendrappa ${ }^{2}$, V.D. Sheela ${ }^{2}$, G. Bharamappa ${ }^{3}$, \\ and Ganesh Halikatti ${ }^{4}$ \\ Department of Genetics and Plant Breeding, UAS, Raichur, Karnataka, India
}

\begin{abstract}
Combining ability on grain yield and its components from line $\times$ tester analysis of thirty rice hybrids (Oryza sativa L.) produced by crossing three newly developed CMS lines and ten testers of local origin were studied. The analysis revealed higher SCA variance than GCA variance for all the characters except plant height indicating the prevalence of non-additive gene action. The line KCMS 45A and testers MSN 36 and KMR 3 were the good general combiners for yield and its major contributing characters. MSN 99 was the only good general combiner among the male parents for earliness and dwarfness. The hybrids KCMS $46 \mathrm{~A} \times \mathrm{MSN} 75$, KCMS 44A $\times$ KMR 4 and KCMS 45A $\times$ KMR 3 were identified as potential hybrids for yield contributing characters based on SCA effects which could be exploited in future rice breeding programme by adopting heterosis breeding strategy. The contribution of testers towards the total variance was found higher than lines and line $\mathrm{x}$ tester interaction suggesting predominant of testers influence for these characters.
\end{abstract}

Keywords: Combining ability, CMS line, Hybrid rice, Yield.

\section{INTRODUCTION}

Rice (Oryza sativa L.) is the principal food crop of India and Asia. The over growing population, demanded the need to increase the productivity of rice crop. Successful use of hybrid rice technology to increase yield through exploitation of heterosis enabled China to increase total production. Success of any plant breeding programme depends on the choice of appropriate genotypes as parents in the hybridization programme. In hybrid programme, choice of suitable parents is of primary

*Corresponding author email: malli3842@gmail.com

${ }^{1}$ Zonal Agriculture Research Station, V.C.Farm, Mandya, Karnataka, India

${ }^{2}$ Department of Genetics and Plant Breeding, UAS, GKVK, Bengaluru, Karnataka, India.

${ }^{3}$ Department of Agricultural Microbiology, UAS, GKVK, Bengaluru, Karnataka, India.

${ }^{4}$ Department of Agricultural Entomology, UAS, Dharwad, Karnataka, India

Received: 12.09 .2013 
importance since per se performance of parents is not always a true indicator of its combining ability in hybrid combination (Swamy et al., 2003). Therefore performance of a $F_{1}$ hybrid depends on choice of parents. Several methods like per se performance, genetic diversity, combining ability etc., have been attempted to select the parents. Among them combining ability analysis offers a powerful tool for estimating the value of a parent to produce superior hybrid.

The combining ability studies of the parents provide information which helps in the selection of better parents for effective breeding strategies. Combining ability analysis also provides information on additive and dominance variance. Its role is important to decide parents, crosses and appropriate hybrid breeding procedure to be followed to exploit heterosis (Salgotra et al., 2009). Keeping this in view, the present investigation was carried out to study the combining ability in order to identify good combiners and superior hybrid combinations.

\section{MATERIAL AND METHODS}

The experimental materials for the present study comprised of three newly developed CMS lines viz., KCMS 44A, KCMS 45A possessing WA type of cytoplasm and KCMS 46A having Kalinga type of cytoplasm and ten testers viz., Thanu, KMR-3, KMR-4, KMR-12, MSN-36, MSN-75, MSN-91, MSN-93, MSN-98 and MSN-99. The testers used for the study was of Indian origin and were well adapted to local condition.

The three lines and ten testers were crossed in a line $\mathrm{x}$ tester manner by spikelet clipping method during summer 2010. Three lines and 10 testers were sown in three staggered fashions keeping five days interval between them so as to synchronize properly for crossing lines with testers. The resulted thirty hybrids along with the parents (B-lines of corresponding A lines and testers) were grown in randomized block design with two replications during summer 2011 at ZARS, V.C., Farm, Mandya, India. Twenty five day old seedlings of hybrids and their parents were transplanted with single seedling per hill with a spacing of $15 \mathrm{~cm}$ between rows and $15 \mathrm{~cm}$ between plants. Each entry was transplanted in two rows of 4 meter length. All the recommended package of practices was followed to ensure good crop growth and development. Five competitive plants were randomly selected to record the observations on grain yield and yield contributing characters viz., plant height $(\mathrm{cm})$, no. of tillers per plant, no. of panicles per plant, panicle length $(\mathrm{cm})$, spikelet fertility (\%), days to $50 \%$ flowering, no. of spikelets per panicle, yield per plant (g), 1000 grain weight (g) and L/B ratio. Combining ability analysis was done using line $\mathrm{x}$ tester method (Kempthorne, 1957).

\section{RESULTS AND DISCUSSION}

Analysis of variance for combining ability revealed the significant differences among the genotypes (Table 1). Variance due to males (testers) was significant for all the characters except for number of tillers per plant and number of panicles per plant while for females (lines) it was significant only for panicle length and days to $50 \%$ flowering. However variance due to lines $\mathrm{x}$ testers interaction were highly significant for all the characters except for plant height and number of days to $50 \%$ flowering. The variance due to crosses differed significantly for all the characters. Thus, suggesting the 
importance of heterosis breeding for improvement of rice. Combining ability analysis revealed that SCA variance was predominant in the inheritance of various characters studied, indicating predominance of non-additive gene action. The SCA variances were higher than the GCA variances for all the characters except plant height, which is in corroboration with earlier findings of Saravanan et al. (2006) and Anandkumar et al. (2004). The proportional contribution of lines, testers and their interactions to total variances showed that testers played dominant role indicating predominant testers influence for these characters (Table 1). The smaller contribution of interactions of the line $\mathrm{x}$ tester than testers, and higher than lines indicated higher estimates of variances due to general combining ability. Nadali (2010) observed higher estimates of GCA variances due to testers in rice.

The estimates of GCA effects of three lines and ten testers with the corresponding standard errors for all the characters are presented in table 2. Among the CMS lines, KCMS 45A was the best general combiner as it showed highly significant GCA effects for number of tillers per plant, number of panicles per plant and yield in desirable (positive) direction but non-significant. Also the KCMS 46A line was very good general combiner for earliness as it had highly negative significant GCA effect for days to $50 \%$ flowering. This line also had high positive significant GCA effect for panicle length and number of spikelets per panicle. Among the testers, MSN 36 was the best general combiner for important characters like number of spikelets per panicle and yield per plant. While KMR-3 was best general combiner for number of tillers per plant, number of panicles per plant, spikelet fertility and 1000 grain weight which showed highly significant GCA effects in desirable direction. Another tester, MSN 99 had highest significant negative GCA effects for days to $50 \%$ flowering and plant height indicating as a good combiner in desired direction for earliness and plant height. The tester MSN 93 had highest positive significant GCA value for panicle length and the tester MSN 91 showed good general combining ability for L/B ratio. Higher GCA effects in parents was also reported earlier by Swamy et al. (2003), Anandkumar et al. (2004), Jagadeeasan and Ganesan (2006) and Saidaiah et al. (2010).

The overall GCA status of parents was calculated based on the method suggested by Mohan Rao (2001). From the results, it was evident that the lines KCMS 45A and KCMS 46A had high $(\mathrm{H})$ overall GCA status (Table.2). Whereas, among the testers, Thanu, KMR-3, KMR-4, MSN-36, MSN-93 and MSN 98 possessed high (H) overall GCA status. These results are in line with earlier reports of Swamy et al. (2003), Saidaiah et al. (2010).

The estimate of SCA effects with their respective standard error for each character in thirty cross combinations are presented in table 3 . None of the crosses exhibited high SCA effects for all the characters studied. The majority of the crosses showed significant SCA effects, which involved at least one parent having high GCA effects. Only two out of thirty crosses, having positively significant SCA effects for grain yield per plant of which the highest being KCMS 46A $\times$ MSN 75, this hybrid also had highly significant SCA values for spikelet fertility and highly negative significant SCA effect for earliness indicating this cross is good specific combiner for earliness. 
Another hybrid KCMS 45A $\times$ KMR 3 was found superior for number of tillers per plant and number of panicles per plant. None of the hybrids showed significant SCA effects for plant height. The cross KCMS 44A $\times$ KMR 4 had high positive significant SCA values for panicle length and numberr of spikelets per panicle. The hybrids, KCMS 45A $\times$ MSN 75 and KCMS 46A $\times$ MSN 93 were good specific combiners for 1000 grain weight and L/B ratio respectively. These results are in conformity with the earlier findings of Jagadeeasan and Ganesan (2006) and Saidaiah et al. (2010).

Out of thirty hybrids studied fifteen hybrids exhibited high $(\mathrm{H})$ overall GCA status and fifteen crosses exhibited low (L) overall GCA status. All the fifteen crosses with high overall SCA effect has parents with all types of combination of GCA effect viz., $\mathrm{H} \times \mathrm{H}, \mathrm{H} \times \mathrm{L}$ and $\mathrm{L} \times \mathrm{L}$ suggesting the action of additive, non additive gene action and also overdominance and epistasis, respectively. These results are in agreement with the earlier reports of Mohan Rao (2001), Swamy et al. (2003), Saidaiah et al. (2010).

\section{CONCLUSION}

The present study on combining ability analysis revealed the preponderance of non additive gene action for all the characters studied. Hence this study insisted that heterosis breeding is more suitable for all the characters. Among the lines KCMS 45A and among the testers MSN 36 and KMR 3 were the good general combiners for majority of yield attributing characters. These best combiners could be utilized in hybrid development breeding programme. The crosses KCMS 46A $\times$ MSN 75, KCMS $44 \mathrm{~A} \times \mathrm{KMR} 4$ and $\mathrm{KCMS} 45 \mathrm{~A} \times \mathrm{KMR} 3$ were identified as most promising for yield based on $S C A$ effects. Hence these could be used for the exploitation of heterosis for yield and related characters.

\section{REFERENCES}

Anandkumar, Singh, N. K. and Chaudhary, V.K. 2004. Line $\mathrm{x}$ tester analysis for grain yield and related characters in rice. Madras Agricultural Journal, 91 (4-6): 211214

Jagadeesan, S. and Ganesan, J. 2006. Combining ability in rice (Oryza sativa L.). Indian Journal of Agricultural Research, 40 (2): 139 - 142

Kempthorne, O. 1957. An introduction to genetic statistics. John Wiley and Sons, New York, USA pp: $468-473$

Mohan Rao, A. 2001. Heterosis as a function of genetic divergence in sunflower (Helianthus annus.). Ph.D. thesis, Acharya,N.G. Ranga Agricultural University, Hyderbad, pp.42-43

Nadali, B. J. 2010. Heterosis and combining ability analysis for yield and related traits in hybrid rice. International Journal of Biology, 2(2): 222-231

Saidaiah, P., Sudheer Kumar, S. and Ramesha, M.S. 2010. Combining Ability Studies for Development of New Hybrids in Rice over Environments. Journal of Agricultural Science, 2 (2): 225-233 
Salgotra, R.K., Gupta, B.B. and Praveen Singh. 2009. Combining ability studies for yield and yield components in basmati rice. Oryza, 46 (1): 12-16

Saravanan, K., Ramya, B., Satheesh Kumar, P. and Sabesan, T.2006. Combining ability for yield and quality characters in rice (Oryza sativa L.). Oryza, 43 (4): 274-277

Swamy, M.H., Gururaja Rao, M.R. and Vidyachandra, B. 2003. Studies on combining ability in rice hybrids involving new CMS lines. Karnataka Journal of Agricultural Science, 16 (2): 228-233. 


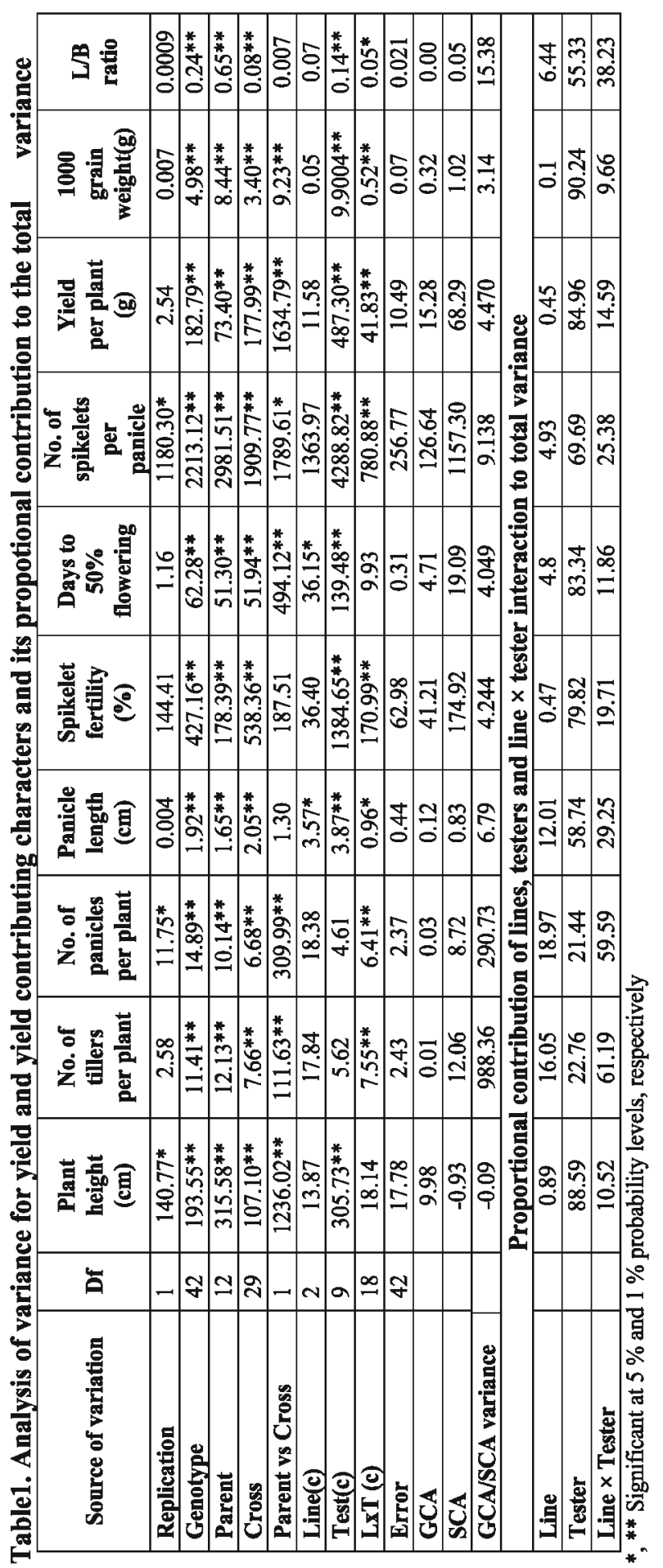




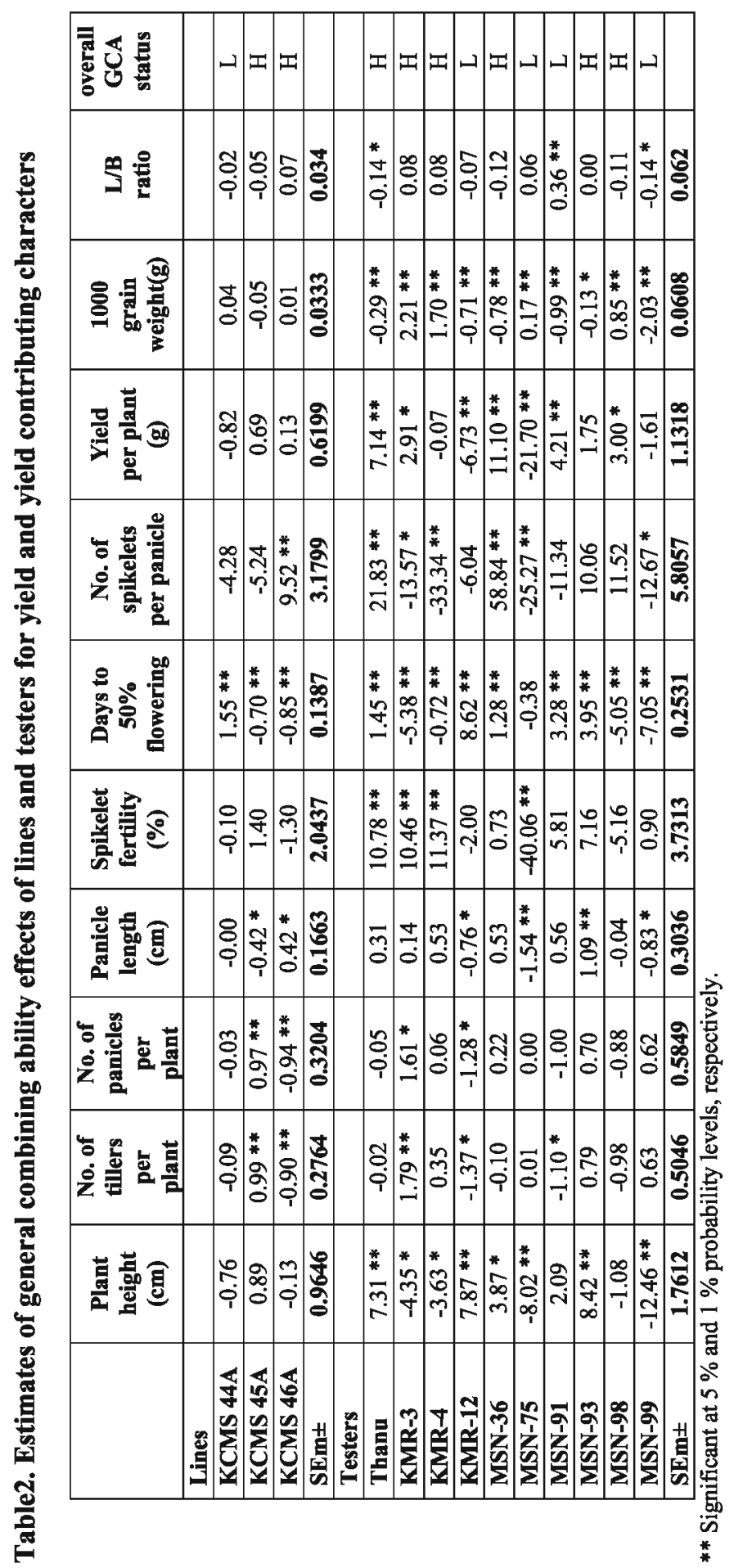




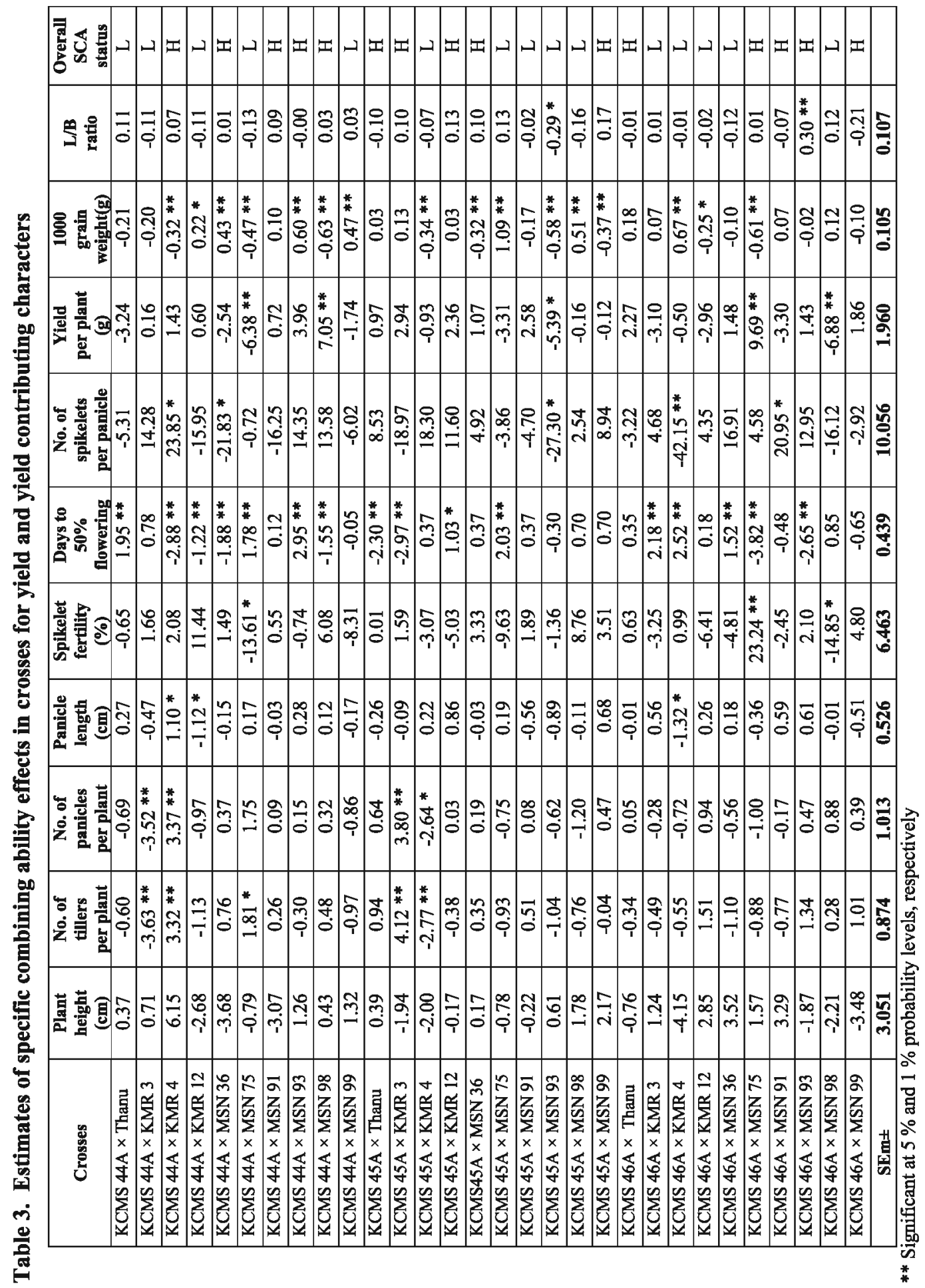

